\title{
Changes in consultants' responsibilities
}

A number of College Committees have considered the procedure which should be followed when a consultant changes his or her specialty. Instances have been given of changes from psychogeriatrics to mental handicap or from general psychiatry to forensic psychiatry. Sometimes this may be a gradual process, when a special interest of one or two sessions gradually grows to occupy the majority of sessions. Sometimes it is a whole-time transfer to fill a gap.

In many ways, it is desirable for consultants to have changes in interests and activities during their careers. At the same time, it is important that:

(a) patients are treated by people with appropriate skills and

(b) that trainee doctors and other staff are trained and led by competent consultants with adequate practical and theoretical knowledge.

The College should therefore be assured of the consultant's past and future training and current competence.

The following procedures should be followed:

(a) All members of the College should be made aware of the College's concern in this matter.
Changes in specialty should be treated very seriously and not undertaken or approved on a casual basis.

(b) The Regional Adviser should be notified of any projected change and he/she should take advice from the Regional Representative, if necessary on the past training and practice of the consultant, and the arrangements for future training.

(c) Health Authorities should make arrangements to ensure that consultants considering or making such changes should be provided with appropriate training as recommended by the College.

(d) Visiting teams approving general or higher training should pay particular attention to the capacity of these consultants to train junior or senior trainees.

Dr J. L. T. BIRLEY President

Dr A. GATH

Registrar

Approved by Council, 23 October 1989

\section{Report from the Public Education Committee}

Each Division of the College has been invited to nominate two Regional Public Education Officers (RPEOs) whose role is to promote and formulate public education initiatives at a divisional level. The following members have agreed to take on this role: Chiltern and Thames Valley Division: $\mathrm{Dr} C$. Hallstrom (Charing Cross Hospital, London) and vacancy; East Anglian Division: Dr G. Lloyd (The Royal Free Hospital, London) and Dr W. R. Guirguis (St Clement's Hospital, Ipswich); Irish Division: Dr G. Loughrey (Downshire Hospital, Downpatrick) and Dr C. Smith (Central Mental Hospital, Dundrum); Midlands Division: Dr R. G. Jones (Queens Medical Centre, Nottingham) and Dr B. S. Sekhawat (New Cross Hospital,
Wolverhampton); North East Division: Dr A. S. Zigmond (High Royds Hospital, Ilkley) and Dr J. Scott (St Nicholas Hospital, Newcastle upon Tyne); North West Division: Dr M. Forth (Royal Liverpool Hospital, Liverpool) and Dr W. Charles (Victoria Hospital, Blackpool); Scottish Division: Chairman of Media Group: Dr E. B. Ritson (Royal Edinburgh Hopital, Edinburgh); Southern Division: Dr J. R. W. Christie-Brown (The Maudsley Hospital, London) and vacancy; South West Division: Dr R. Williams (Bristol Royal Hospital for Sick Children, Bristol) and Dr C. Davies (Weston Lodge Hospital, Bath); Welsh Division: Dr M. Shooter (Preswylfa Child and Family Centre, Cardiff). 